\title{
CARACTERIZAÇÃO DA VEGETAÇÃO DA CAATINGA DO SUL DO PIAUÍ PARA GERAÇÃO DE ENERGIA
}

\author{
Martha Andreia Brand ${ }^{1 *}$, Luciane da Costa Oliveira ${ }^{2}$, Stephenson Ramalho Lacerda ${ }^{3}$, \\ Eliseu Rossato Toniolo ${ }^{4}$, Geraldo Leal Júnior ${ }^{5}$, Ricardo Barreto Campello ${ }^{5}$ \\ ${ }^{1 *}$ Universidade do Estado de Santa Catarina, Lages, Santa Catarina, Brasil - martha.brand@udesc.br \\ ${ }^{2}$ Instituto Federal de Santa Catarina, Lages, Santa Catarina, Brasil - luciane.costa@ifsc.edu.br \\ ${ }^{3}$ Empresa Mata Branca, Crato, Ceará, Brasil - tessonpb@yahoo.com.br \\ ${ }^{4}$ GEOPHOTO-Geoprocessamento e Sensoriamento Remoto, Fortaleza, Ceará, Brasil - eliseurt @yahoo.com.br \\ ${ }^{5}$ Crato, Ceará, Brasil - projeto@ baydejbc.com.br
}

Recebido para publicação: 22/06/2012 - Aceito para publicação: 09/03/2015

\begin{abstract}
O manejo sustentável da caatinga é fundamental para a preservação desse ecossistema e manutenção das populações rurais. Dessa forma, este trabalho teve como objetivo caracterizar a vegetação de uma área de caatinga localizada no sul do Piauí, visando a sua utilização para a geração de energia. Em 32 parcelas de $20 \times 20 \mathrm{~m}$, foram realizados o inventário florestal, para a quantificação da biomassa (troncos sem galhos) e a caracterização da vegetação, sendo identificadas 70 espécies, distribuídas em 19 famílias. A quantidade de biomassa produzida na área foi em média de 164 t/ha ou $153 \mathrm{~m}^{3} / \mathrm{ha}$. A vegetação apresentou ainda altura média de $5,6 \mathrm{~m}$, com 4205 indivíduos/ha. A floresta tem densidade populacional alta, com predominância de indivíduos com diâmetro pequeno (52\% da população entre 2 a $5 \mathrm{~cm}$ de diâmetro). A maior quantidade de biomassa está concentrada nas classes diamétricas superiores a $10 \mathrm{~cm}$ ( $84 \%$ do total de biomassa úmida). A alta diversidade diamétrica requer tratamento especial da biomassa para geração de energia. De forma geral, a quantidade de biomassa gerada na área de estudo é alta e com grande potencial para a geração de energia.

Palavras chave: Biomassa; inventário; lenha; levantamento florístico.
\end{abstract}

Resumo

\begin{abstract}
Characterization of caatinga vegetation in NE Brazil for power generation. The sustainable management of the savanna is fundamental to the preservation of this ecosystem and maintenance of rural populations. Thus, this study aimed to characterize the vegetation of an area of savanna located in southern Piauí, aiming its use for power generation. Thirty-two plots of $20 \mathrm{~m} \times 20 \mathrm{~m}$ were deployed. Forest inventory of plots were performed for the quantification of biomass (branchless trunks) and characterization of vegetation. Seventy species, divided into nineteen families were identified. The amount of biomass produced in the area averaged $164 \mathrm{t} / \mathrm{ha}$ or $153 \mathrm{~m}^{3} / \mathrm{h}$. The vegetation still had an average height of $5.6 \mathrm{~m}$, with 4205 trees / ha. The forest has a high population density, with a predominance of individuals with small diameter $(52 \%$ of the population between $2-5 \mathrm{~cm}$ in diameter). The largest amount of biomass is concentrated in the upper $10 \mathrm{~cm}$ diameter classes $(84 \%$ of wet biomass). The high diametric diversity requires special treatment of biomass for power generation. In general, the amount of biomass generated in the study area is high, with great potential for power generation.
\end{abstract}

Keyword: Biomass; firewood; floristic survey; inventory.

\section{INTRODUÇÃO}

Segundo o Sistema Nacional de Informações Florestais, a área de caatinga no Brasil, levantada pela Fundação Instituto Brasileiro de Geografia e Estatística (IBGE), em 2009, era de 844.453 km², representando 9,92\% da área territorial do Brasil (BRASIL, 2012).

Caatinga é o tipo de vegetação que cobre a maior parte da área com clima semiárido da região Nordeste do Brasil (GIULIETTI et al., 2004). Porém, segundo Sampaio (2010), a conceituação de caatinga como sendo uma vegetação exclusivamente regional deixa em aberto sua ligação com

FLORESTA, Curitiba, PR, v. 45, n. 3, p. 477 - 486, jul. / set. 2015.

Brand, M. A. et al.

ISSN eletrônico 1982-4688 / ISSN impresso 0015-3826

DOI: $10.5380 /$ rf.v45i3.27753 
classificações mais gerais. Internacionalmente, ela tem sido incluída como uma das florestas ou matas secas tropicais decíduas (OLIVEIRA FILHO et al., 2006). Essa classificação a torna indistinguível das matas secas nordestinas, que têm sido vistas, regionalmente, como um grupo vegetacional à parte, sendo que no extremo mais seco das caatingas elas poderiam ser enquadradas como um arbustal espinhoso com suculentas (OLIVEIRA FILHO et al., 2006) e têm sido denominadas, também, de vegetação caducifólia espinhosa (ALCOFORADO-FILHO et al., 2003). Na classificação brasileira, a caatinga é uma savana estépica, o que a colocaria junto aos cerrados e outras vegetações abertas. Sem dúvida, a diversidade de fisionomias presentes no domínio das caatingas dificulta o enquadramento em qualquer tipologia e sempre haverá áreas de exceção (SAMPAIO, 2010).

Em se tratando de usos aplicados às espécies componentes dessa categoria de vegetação, as mais importantes são: construção civil (70,49\% das espécies), medicamentos $(65,57 \%)$ (SANTOS et al., 2008), e combustível (54,91\%) (FRANCELINO et al., 2003, SANTOS et al., 2008, RAMOS et al., 2008, ALVAREZ et al., s/d). Como combustível, a lenha pode ser utilizada como fonte energética para indústria, comércio e domicílios, além de carvão vegetal (PAREYN, 2010). Segundo Sampaio (2010), principalmente nas cercanias dos grandes centros consumidores, a produção de lenha, que antes era um subproduto da abertura de áreas da agricultura, passou a ser uma atividade independente.

Sampaio (2010) lembra que a agricultura itinerante deixou um legado de áreas degradadas, principalmente nas encostas, onde a erosão arrastou parte dos solos já originalmente rasos, e a remoção de nutrientes. A degradação do solo, sem reposição, reduziu a capacidade de produção nos anos de boas chuvas, resultando em baixa produtividade e no abandono gradativo desse tipo de agricultura nas áreas menos favorecidas, cedendo lugar a pecuária e a produção de lenha. Estas, por sua vez, são formas de uso mais sustentáveis e a elas se deve a preservação de grande parte do que ainda resta de vegetação nativa, devendo haver mais pesquisas e regulamentação para esses setores.

Paupitz (2010) e Ramos e Albuquerque (2012) também destacam que a sazonalidade é outra característica da produção agrícola e da coleta de lenha da caatinga para geração de energia. A incorporação de faixas florestais para a produção de lenha, carvão vegetal, extração de fibras, frutos e ervas medicinais pode permitir a geração de receitas complementares à renda familiar, especialmente durante as estiagens, depois das colheitas e durante os períodos pré-safra. Segundo Brand et al. (2009), o uso alternativo do solo sem a implantação concomitante de planos de manejo florestal que garantam a manutenção da cobertura vegetal nativa pode levar ao colapso ambiental do ecossistema existente. Além das vantagens socioambientais, projetos de uso sustentável são fundamentais sob os aspectos econômicos e ambientais para regiões como o Nordeste.

De acordo com a Lei ${ }^{\circ} 11.284$ (BRASIL, 2006), é possível viabilizar a exploração florestal em grandes extensões, criando atividades rentáveis para as populações locais e garantindo a gestão sustentável dos recursos, incorporando grandes áreas florestais para a produção, em escala industrial, de lenha e carvão vegetal, tanto no oeste da Bahia como no sul do Piauí.

Por outro lado, muitas das argumentações contrárias ao uso de sistemas nativos para a geração de energia não têm bases científicas suficientes, oriundas de trabalhos exaustivos de quantificação e qualificação da biomassa produzida pela floresta, bem como sobre a caracterização e classificação correta do sistema florestal. Assim, estudos dessa natureza determinarão a viabilidade de uso de sistemas nativos sob regime sustentável, para o uso na geração de energia (BRAND et al., 2009).

Portanto, este trabalho teve como objetivo analisar uma área de vegetação da caatinga localizada no sul do Piauí, através de caracterização da vegetação e inventário florestal, visando a sua utilização sustentável para a geração de energia.

\section{MATERIAL E MÉTODOS}

\section{Descrição da área de estudo}

O trabalho foi desenvolvido em um empreendimento privado denominado Condomínio Fazenda Chapada do Gurguéia, na região sul do Piauí. As terras do condomínio pertencem a dois municípios: Redenção do Gurguéia e Morro Cabeça no Tempo. As sedes desses municípios se localizam, respectivamente, a noroeste e a sudeste da sede da propriedade, que está contida em torno das

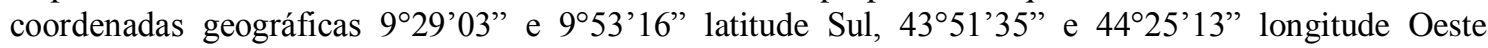
(TONIOLO et al., 2005) (Figura 1). 


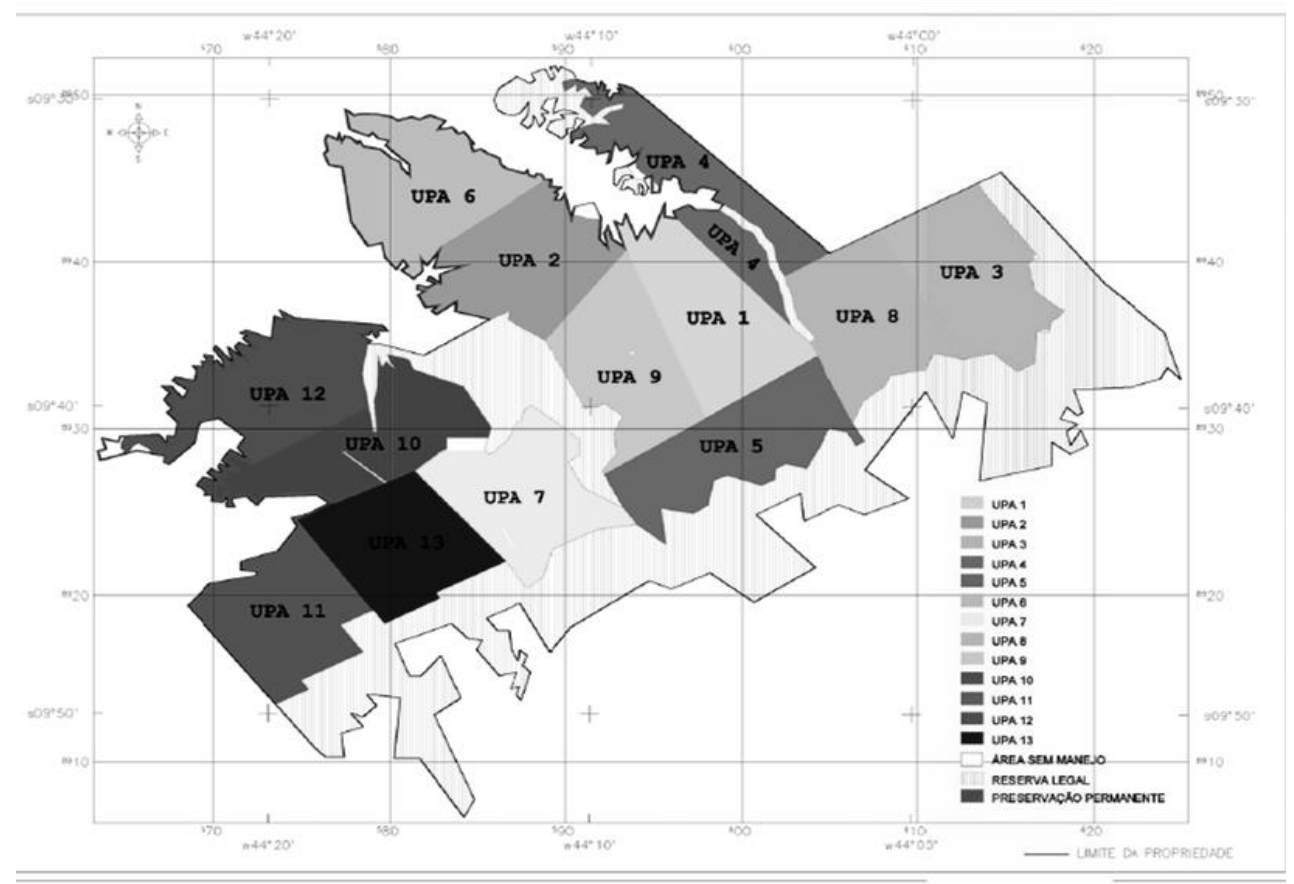

UPA: Unidade de Produção Anual, com área de 6000 ha.

Figura 1. Área do projeto de Manejo Sustentável da Caatinga - Condomínio Fazenda Chapada do Gurguéia, localizada nos municípios de Redenção do Gurguéia e Morro Cabeça no Tempo.

Figure 1. Area of the project Sustainable Management of the Caatinga - Chapada Gurguéia farm, located in the municipalities of Redenção do Gurguéia and Morro Cabeça no Tempo.

Segundo Toniolo et al. (2005), o empreendimento tem área total de 114.755 ha, localizado no topo plano de uma chapada sedimentar arenítica, denominada "Serra Vermelha". A área do condomínio situa-se integralmente na Grande Unidade de Paisagem das Chapadas Intermediárias e na Unidade Geoambiental das Chapadas do Extremo Sul do Piauí.

A área sob regime de manejo do projeto para o uso vegetal na geração de energia é de 78 mil ha. $\mathrm{O}$ ciclo de corte foi definido como sendo de 13 anos, ou seja, a cada 13 anos retorna-se à mesma área de produção anual, denominada no projeto de manejo com a sigla UPA, para novo ciclo de corte. Dessa forma, a área sob manejo foi dividida em 13 UPAs (Unidades de Produção Anual), tendo cada UPA uma área de 6000 ha (Figura 1).

A região situa-se na transição de clima árido (E) para semiárido (D) e com predominância do clima subúmido seco (ANDRADE JÚNIOR et al., 2004). A temperatura máxima é de $31,4^{\circ} \mathrm{C}$ e a mínima de $19,1^{\circ} \mathrm{C}$, com médias anuais de $25,2^{\circ} \mathrm{C}$. A umidade relativa do ar é de $63,8 \%$ e a precipitação média é de 848,3 mm (MEDEIROS et al, 2013).

A vegetação existente dentro do empreendimento pode ser denominada fitogeograficamente de Savana Estépica Florestada (caatinga), segundo a classificação do IBGE (1992), constituída por indivíduos micro e ou nanofanerófitos, com média de $5 \mathrm{~m}$, excepcionalmente ultrapassando os $7 \mathrm{~m}$ de altura, mais ou menos densos, com grossos troncos e esgalhamento bastante ramificado, em geral providos de espinhos ou acúleos, com total descidualidade na época desfavorável.

\section{Caracterização da vegetação e inventário florestal}

$\mathrm{O}$ inventário foi feito através de amostragem aleatória. Nessa amostragem, parcelas foram demarcadas no mapa e em campo de forma aleatória, sem nenhuma tendência ou escolha prévia de alguma categoria de solo, vegetação ou outra característica que possa influenciar ou estratificar os dados. A metodologia se baseou na proposta PNUD/FAO/IBAMA/BRA/87/007 para o semiárido (PROJETO PNUD, 1992).

O trabalho de campo consistiu na demarcação de 32 parcelas de 20 × 20 m, a uma distância mínima de 50 metros da bordadura da floresta. Foram medidos os diâmetros à altura do peito (DAP) de

FLORESTA, Curitiba, PR, v. 45, n. 3, p. 477 - 486, jul. / set. 2015.

Brand, M. A. et al.

ISSN eletrônico 1982-4688 / ISSN impresso 0015-3826 
todos os indivíduos com mais de $2 \mathrm{~cm}$ de DAP e a altura total dos indivíduos, com hipsômetro (PROJETO PNUD, 1992). Em todas as parcelas foi realizado também o levantamento florístico para a caracterização da vegetação existente.

O levantamento florístico foi realizado através de coleta e identificação de espécies nas parcelas inventariadas, com o apoio de mateiros, e a identificação posterior das espécies realizada por especialistas na vegetação da região. A classificação botânica das espécies foi feita a partir do sistema APG III (BOTANICAL JOURNAL OF THE LINNEAN SOCIETY, 2009) para as famílias.

O critério de análise dos dados de levantamento florístico para determinação das espécies de maior ocorrência foi a abundância das mesmas na área de estudo.

Nas 32 parcelas analisadas, todas as árvores foram derrubadas e traçadas com comprimento médio de $1 \mathrm{~m}$, para a confecção das pilhas e determinação do volume estéreo e da massa úmida (somente troncos, sem galhos e folhas), por meio de balança de campo, com precisão de $0,5 \mathrm{~kg}$.

Para a cubagem, a pilha foi medida em seis cotas de altura e largura, e duas cotas de comprimento. Com essas cotas, foi calculado o metro estéreo. Para os cálculos efetuados no Plano de Manejo, foi utilizado o fator de conversão de 2,65 metro estéreo/ $\mathrm{m}^{3}$, de acordo com o PROJETO PNUD (1992).

Os resultados dendrométricos foram obtidos pelas fórmulas apresentadas nas equações 1,2 e 3 .

$$
\text { Área basal }(g)=\left(\pi \times D A P^{2}\right) \div 4
$$

em que: DAP é o diâmetro à altura do peito.

$$
\text { Altura }(h)=L \times(\tan \sigma 1+\tan \sigma 2)
$$

em que: $\mathrm{L}=$ distância entre o operador e a árvore; $\operatorname{tg} \sigma 1=$ tangente do ângulo de visada da base da árvore; $\operatorname{tg} \sigma 2=$ tangente do ângulo de visada do ápice da árvore.

$$
\text { Volume }(v)=g \times h \times F f
$$

em que: $\mathrm{G}=$ área basal; $\mathrm{Ff}$ = fator de forma da espécie.

Por se tratar de um trabalho de caracterização da vegetação, os dados foram analisados de forma a demonstrar o número de espécies observadas, número de indivíduos na área de estudo, abundância das espécies mais importantes na formação vegetal e quantidade de biomassa disponível em termos de massa e volume.

\section{RESULTADOS E DISCUSSÃO}

\section{Caracterização da vegetação}

Com relação à caracterização da vegetação presente na área de estudo, foram identificadas 70 espécies. Destas, 47 foram identificadas até gênero e ou espécie, distribuídas em 19 famílias (Tabela 1) e 23 não foram identificadas botanicamente, nem em nível de família. Durante os trabalhos de campo e posteriormente, não foi possível a identificação das 23 espécies anteriormente relacionadas. No entanto, é possível afirmar se tratar de espécies diferentes entre si e das demais identificadas.

Entre as 20 mais abundantes (com valores de abundância superiores a 1,00\%), estavam as seguintes espécies: muta (Eugenia sp.1) (6,72\%); canela-de-velho (Cenostigma gardnerianum) $(6,26 \%)$, ata-braba (Annona sp.1) (5,29\%), marmelada (Desmodium discolor) (4,88\%), joão-mole (Pisonia sp.) $(4,86 \%)$, araçá (Psidium araca) (4,68\%), canduru (Brosimum gaudichaudii) (3,45\%), unha-de-gato (Mimosa malacocentra) (3,23\%), catuaba (Erythroxylum vaccinifolium) (3,11\%), mororó (Bauhinia sp.) (2,93\%), jatobá (Hymenaea eriogyne) (2,68\%), pereiro (Aspidosperma pyricollum) (2,34\%), murici (Byrsonima sp.) (2,14\%), alecrim (Rosmarinus officinalis) (2,02\%), pau-d'óleo (Copaifera_langsdorffii) $(1,78 \%)$, goiabinha (Eugenia sp.2) (1,76\%), birro cangalheiro (Pterodon polygalaeflorus) $(1,70 \%)$, catambuva (Piptadenia moniliformis) $(1,53 \%)$, fava-de-morcego (Pterodon pubescens) $(1,43 \%)$ e banhade-galinha (Swartzia psilonema) (1,09\%). Essas espécies representam $63,88 \%$ da população amostrada. A somatória da abundância das espécies apresentadas na tabela 1 é de 77,45\%, sendo que o restante, $22,55 \%$, é relativo à somatória das 23 espécies que não foram identificadas. 
Tabela 1. Identificação e abundância de espécies florestais presentes em área de caatinga no sul do Piauí. Table 1. Identification and abundance of species from savanna area in southern Piauí, Brazil.

\begin{tabular}{|c|c|c|}
\hline Família & Nome científico & Abundância (\%) \\
\hline \multirow[t]{2}{*}{ Annonaceae } & Annona sp.1 & 5,29 \\
\hline & Annona sp. 2 & 0,16 \\
\hline Apocynaceae & Aspidosperma pyricollum Muell. Arg. & 2,34 \\
\hline \multirow[t]{3}{*}{ Bignoniaceae } & Anemopaegma glaucum Mart. & 0,98 \\
\hline & Anemopaegma sp. & 0,80 \\
\hline & Handroanthus avellanedae Lorentz ex Griseb. & 0,71 \\
\hline Boraginaceae & Cordia sp. & 0,02 \\
\hline Combretaceae & Terminalia fagifolia Mart. \& Zucc. & 0,58 \\
\hline Erythroxylaceae & Erythroxylum vaccinifolium Mart. & 3,11 \\
\hline \multirow[t]{3}{*}{ Euphorbiaceae } & Croton hemiargyreus Müll.Arg. & 0,12 \\
\hline & Manihot piauhyensis Ule & 0,32 \\
\hline & Sebastiania macrocarpa Müll.Arg. & 0,04 \\
\hline \multirow[t]{20}{*}{ Fabaceae } & Acacia piauhiensis Benth. & 0,04 \\
\hline & Bauhinia sp.1 & 2,93 \\
\hline & Bauhinia sp.2 & 0,90 \\
\hline & Caesalpinia sp. & 0,61 \\
\hline & Cenostigma gardnerianum Tul. & 6,26 \\
\hline & Centrolobium sp. & 1,00 \\
\hline & Copaifera langsdorfii Desf. & 1,78 \\
\hline & Desmodium discolor Vogel & 4,88 \\
\hline & Dimorphandra gardneriana Tul. & 0,75 \\
\hline & Hymenaea eriogyne Benth. & 2,68 \\
\hline & Hymenaea stigonocarpa Mart. & 1,00 \\
\hline & Mimosa acutistipula Benth. & 0,12 \\
\hline & Mimosa malacocentra (Mart.) Benth. & 3,23 \\
\hline & Peltogyne sp. & 0,61 \\
\hline & Piptadenia macrocarpa Benth. & 0,02 \\
\hline & Piptadenia moniliformis Benth. & 1,53 \\
\hline & Pterodon polygalaeflorus Benth. & 1,70 \\
\hline & Pterodon pubescens Benth. & 1,43 \\
\hline & Swartzia psilonema Hams. & 1,09 \\
\hline & Zollernia paraensis Huber & 0,93 \\
\hline Lamiaceae & Rosmarinus officinalis L. & 2,02 \\
\hline Malpighiaceae & Byrsonima sp. & 2,14 \\
\hline Malvaceae & Luehea sp. & 0,90 \\
\hline Moraceae & Brosimum gaudichaudii Trécul & 3,45 \\
\hline \multirow[t]{4}{*}{ Myrtaceae } & Eugenia sp.1 & 6,72 \\
\hline & Eugenia sp.2 & 1,76 \\
\hline & Eugenia sp.3 & 0,16 \\
\hline & Psidium araca Raddi & 4,68 \\
\hline Nyctaginaceae & Pisonia sp. & 4,86 \\
\hline \multirow[t]{2}{*}{ Olacaceae } & Ximenia Americana $\mathrm{L}$. & 0,44 \\
\hline & Ximenia coriacea Engl. & 1,00 \\
\hline Rutaceae & Pilocarpus microphyllus Stapf. & 0,63 \\
\hline Salicaceae & Casearia guianensis (Aubl.) Urb. & 0,08 \\
\hline Sapotaceae & Manilkara sp. & 0,02 \\
\hline Solanaceae & Solanum sp. & 0,63 \\
\hline
\end{tabular}

A abundância é definida pela porcentagem de participação de cada espécie por ha em relação ao número total de indivíduos.

A vegetação apresentou altura média de 5,6 m, com 4205 indivíduos/ha, representando bem as características da vegetação segundo a classificação do IBGE (1992) para altura e densidade populacional. 
Francelino et al. (2003), em levantamento florístico realizado em caatinga no Rio Grande do Norte, encontraram 46 espécies de árvores nativas. As espécies mais bem distribuídas pelas unidades amostrais foram justamente as de caráter pioneiro, como o marmeleiro (Croton hemiargyreus), com frequência de 93\%, seguido pela catingueira (Caesalpinea pyramidalis) e pelo mororó (Bauhinia forficata), com 82 e 75\%, respectivamente. Essas três espécies também foram identificadas neste estudo, juntamente com mais 11 espécies que foram comuns aos estudos de Francelino et al. (2003) e ao aqui apresentado. As espécies identificadas nos dois estudos foram: ameixa (Ximenia americana); angico-debezerro, catanduva ou quipembe (Piptadenia moniliformis); café-bravo (Casearia guianensis); catingade-porco (Caesalpinia sp.); espinheiro-preto ou bravo (Acacia piauhiensis); maniçoba (Manihot piauhyensis); marmeleiro-preto (Croton hemiargyreus); miroró/mororó (Bauhinia sp.); murici-da-mata (Byrsonima sp.); pereiro-da-serra (Aspidosperma pyricollum); e unha-de-gato ou rompe-gibão (Mimosa malacocentra).

No estudo feito por Ramos et al. (2008), em Caruaru, Pernambuco, foram encontradas 12 espécies em comum com esse estudo, entre elas Aspidosperma pyricollum, Bauhinia sp. (mororó), Desmodium discolor, Manihot piauhyensis, Byrsonima sp. (murici) e Acacia piauhiensis.

Alcoforado-Filho et al. (2003) realizaram um levantamento florístico e fitossociológico em uma área do município de Caruaru, $\mathrm{PB}$, no agreste no Planalto da Borborema. No componente arbóreo, os autores identificaram 39 espécies, distribuídas por 19 famílias, com destaque para Euphorbiaceae e Mimosaceae. Os resultados mostraram que a densidade foi de 3.810 indivíduos/ha e que os elementos arbóreos mais conspícuos da área de estudo foram: Schinopsis brasiliensis (Anacardiaceae); Caesalpinia pyramidalis e Bauhinia cheilanta (Caesalpiniaceae); e Maprounea guianensis (Euphorbiaceae).

Os resultados obtidos para a vegetação no sul do Piauí também apresentaram predominância de espécies das famílias Euphorbiaceae e Fabaceae (atualmente a família Mimosaceae está incluída na Fabaceae), como a área estudada por Alcoforado-Filho et al. (2003) em Pernambuco, assim como o mesmo número de famílias, no entanto, com maior número de espécies componentes da vegetação e maior número de indivíduos por unidade de área.

De forma geral, a comparação com a literatura permite destacar que a vegetação da caatinga em diferentes regiões do Nordeste apresenta peculiaridades e variações regionais, principalmente em termos de densidade populacional e composição florística.

\section{Inventário florestal}

$\mathrm{Na}$ tabela 2, o número médio de indivíduos por hectare indica que a floresta tem densidade alta, com muitos indivíduos por unidade de área, porém com predominância de indivíduos com diâmetro pequeno. Os indivíduos estão distribuídos de forma que $52 \%$ da população têm entre 2 e $5 \mathrm{~cm}$ de diâmetro (diâmetro médio de $3 \mathrm{~cm}$ ) e $24 \%$ entre 6 a $9 \mathrm{~cm}$ (diâmetro médio de $7 \mathrm{~cm}$ ), totalizando $76 \%$ da população com diâmetros entre 2 a $9 \mathrm{~cm}$. No entanto, essa classe diamétrica tem pouca representação em termos de peso de biomassa e volume para a geração de energia, representando apenas $16 \%$ da quantidade total de biomassa disponível para esse fim. A maior quantidade (peso) de biomassa está concentrada a partir dos $10 \mathrm{~cm}$ de diâmetro, representando $84 \%$ do total de biomassa úmida disponível para geração de energia.

O uso do material com menor dimensão requer o ajuste de equipamentos e máquinas para colheita, coleta, transporte e armazenamento. Material com pequeno diâmetro é mais difícil de coletar, necessitando de garras com menor abertura e que não são aplicáveis para biomassa de maior diâmetro. Na coleta, a contaminação por material estranho é maior, causando aumento da porcentagem de cinzas e consequentemente mais resíduos no processo de combustão e perdas no transporte, por queda do material. Além disso, a biomassa de menor dimensão tem maior rapidez na biodegradação. Portanto, a permanência desse material na floresta pode ser desejável, pois propicia cobertura do solo, retenção da umidade e disponibilização de nutrientes para a regeneração da floresta.

A quantidade total em massa, para a área de estudo, foi em média de 164 t/ha. No entanto, considerando que o material entre 2 e $5 \mathrm{~cm}$ de diâmetro permaneça no solo, ter-se-ia uma disponibilidade média de 157 toneladas/ha de massa úmida ou $147 \mathrm{~m}^{3} /$ ha de biomassa disponível para geração de energia.

Em 15 parcelas $(46,88 \%)$, das 32 analisadas, a maior quantidade de biomassa está concentrada entre os diâmetros de 18 a $25 \mathrm{~cm}$. Em 23\% das parcelas, a maior quantidade de biomassa está entre 26 e $99 \mathrm{~cm}$ de diâmetro, e em $17 \%$ delas o maior volume e massa de biomassa se encontra entre os diâmetros de 10 a $13 \mathrm{~cm}$. Essa informação é importante, pois demonstra que a maior quantidade de 
biomassa disponível para utilização na geração de energia terá diâmetro variando entre 10 e $99 \mathrm{~cm}$ (pela formação florestal avaliada, os diâmetros extremos próximos de $99 \mathrm{~cm}$ serão raros).

Tabela 2. Dados dendrométricos da vegetação existente em área de caatinga no sul do Piauí.

Table 2. Dendrometric data of the existing vegetation in the area of savanna in southern Piauí, Brazil.

\begin{tabular}{lcccccc}
\hline Classe diamétrica & Número de & Diâmetro & \multicolumn{2}{c}{ Massa úmida (t/ha) } & \multicolumn{2}{c}{ Volume $\left(\mathbf{m}^{\mathbf{3}} / \mathbf{h a}\right)$} \\
\cline { 5 - 7 } DAP $(\mathbf{c m})$ & indivíduo/ha & médio $(\mathbf{c m})$ & Média & Erro padrão & Média & Erro padrão \\
\hline 2 a 5 & 2181 & 3 & 6,740 & 0,445 & 6,3 & 0,42 \\
6 a 9 & 991 & 7 & 19,276 & 1,304 & 18,03 & 1,22 \\
10 a 13 & 538 & 10 & 29,419 & 2,053 & 27,51 & 1,92 \\
14 a 17 & 244 & 14 & 29,419 & 2,461 & 27,51 & 2,30 \\
18 a 25 & 203 & 18 & 47,719 & 4,556 & 44,63 & 4,26 \\
26 a 99 & 48 & 30 & 30,994 & 7,390 & 28,99 & 6,91 \\
\hline Total & 4205 & & 163,568 & & 152,97 & \\
\hline
\end{tabular}

Mesmo não retirando da área a biomassa com diâmetros reduzidos, o potencial da vegetação analisada para o uso na geração de energia é alto, comparativamente aos dados de literatura obtidos por Francelino et al. (2003), Alvarez et al. (s/d), Sá (1998) e Brand et al. (2014).

Francelino et al. (2003), trabalhando no estado do Rio Grande do Norte, encontrou valores de $52,6 \mathrm{~m}^{3} / \mathrm{ha}$ com 5794 árvores/ha para caatinga arbustivo-arbórea e 111,18 m³/ha com 5833 árvores/ha para caatinga arbórea, apresentando maior densidade populacional com produção menor de biomassa por unidade de área, em relação ao trabalho aqui apresentado.

Alvarez et al. (s/d), em estudo realizado no Campo Experimental da Caatinga da Embrapa Semiárido em Petrolina, determinou que as espécies arbóreas e arbustivas da caatinga, em área preservada, fornecem o valor médio de $48,39 \mathrm{~m}^{3} / \mathrm{ha}$, constituindo-se importante fonte energética no semiárido. Trabalhos realizados por Sá (1998) no sertão de Pernambuco demonstram valores de $38 \mathrm{~m}^{3} / \mathrm{ha}$ para a caatinga arbustivo-arbórea aberta, $54,69 \mathrm{~m}^{3} / \mathrm{ha}$ para caatinga arbustivo-arbórea fechada e $86,0 \mathrm{~m}^{3} / \mathrm{h}$ a para a caatinga arbórea fechada. Comparativamente, os valores obtidos por Alvarez et al. $(\mathrm{s} / \mathrm{d})$ e Sá (1998) são baixos em relação aos obtidos no sul do Piauí, confirmando a maior potencialidade dessa área para a geração de energia.

Para efeito de comparação, podem ser usados ainda valores de biomassa obtida de resíduos de florestas plantadas com espécies exóticas, cultivadas para uso múltiplo. Nesse contexto, Brand et al. (2014) quantificaram a biomassa produzida por unidade de área em povoamentos de Pinus com diferentes idades, para geração de energia. Os autores constataram que a produção de biomassa por unidade de área variou de 30 (3 e 6 anos) a 95 t/ha (24 anos). Se não for incluída na soma a quantificação da biomassa das folhas, o potencial varia de 13 a 67 t/ha, nas idades de 3 e 24 anos, respectivamente. Assim, o maior potencial produtivo de biomassa está no corte raso ( 24 anos), mesmo tendo número menor de indivíduos por unidade de área (550). Portanto, analisando dados de formações vegetais similares à deste estudo, e mesmo o potencial de biomassa gerado por uma floresta com espécie exótica de uso múltiplo, pode-se afirmar que o potencial de biomassa para geração de energia na área de estudo é alto.

Pode-se destacar ainda que, em termos de geração de energia elétrica, considerando um fator de conversão da termelétrica de $2,2 \mathrm{t}$ de biomassa/MWh de energia elétrica gerada ${ }^{2}$, para uma área de exploração de 6.000 ha/ano (UPA), com produção média de 160 toneladas/ha, seria possível a instalação de uma termelétrica com capacidade de geração de pelo menos $50 \mathrm{MWh}$. Uma usina com esse potencial de geração de energia teria o dobro do tamanho da usina da Tractebel utilizada para o cálculo acima, que está em operação na cidade de Lages, em Santa Catarina.

\footnotetext{
${ }^{1}$ O diâmetro médio observado, juntamente com a disponibilidade da biomassa por classe diamétrica, é importante para o dimensionamento dos picadores florestais ou industriais utilizados em projetos de geração de energia elétrica.

${ }^{2}$ Esse valor é baseado em valores de eficiência obtidos em uma termelétrica cogeradora de Energia da empresa Tractebel Energia S.A - UCLA Lages, localizada em Lages, SC, em operação desde 2005 e que utiliza biomassa florestal para a geração de energia.
}

FLORESTA, Curitiba, PR, v. 45, n. 3, p. 477 - 486, jul. / set. 2015.

Brand, M. A. et al. 


\section{CONCLUSÕES}

- A floresta tem densidade alta, com muitos indivíduos por unidade de área, porém com maior proporção de indivíduos com diâmetros entre 2 e $9 \mathrm{~cm}$.

- As 20 espécies com maior abundância na vegetação representam $63,88 \%$ da população amostrada.

- O uso da biomassa com menor diâmetro não é recomendado, tanto por questões ecológicas, para evitar exportação de nutrientes e propiciar a cobertura do solo, quanto por questões técnicas, devido à necessidade de ajuste de equipamentos para colheita, manuseio e uso na geração de energia.

- A maior disponibilidade de biomassa está nos indivíduos com diâmetros superiores a $10 \mathrm{~cm}$.

- A quantidade de biomassa gerada na área de estudo é alta e com grande potencial para a geração de energia.

\section{AGRADECIMENTOS}

A empresa Tractebel Energia S.A., pelo apoio financeiro através do projeto "Análise da potencialidade de uso de biomassa oriunda de florestas nativas sob manejo sustentável para a geração de energia" (ANEEL 0403-001/2007), ciclo 2006-2007; à empresa JB Carbon S.A, pelo acesso à Fazenda Chapada do Gurguéia; à Universidade do Planalto Catarinense, pelo apoio financeiro.

\section{REFERÊNCIAS}

ALCOFORADO-FILHO, F. G.; SAMPAIO, E. V. S. B.; RODAL, M. J. N. Florística e fitossociologia de um remanescente de vegetação caducifólia espinhosa arbórea em Caruaru, Pernambuco. Acta bot. bras. v. 17, n. 2 , p. $287-303,2003$.

ALVAREZ, I. A.; OlIVEIRA, A. R.; DE OLIVEIRA, V. M. DO N.; GARRIDO, M. A. Potencial energético de área conservada de caatinga em Petrolina, PE. Sem data. Disponível em: <http://www.alice.cnptia.embrapa.br/bitstream/doc/157736/1/OPB2315.pdf>. Acesso em: 10/05/2012.

ANDRADE JÚNIOR, A. S.; BASTOS, E. A.; BARROS, A. H. C.; SILVA, C. O.; GOMES, A. A. N. Classificação climática do estado do Piauí. Teresina: Embrapa Meio-Norte. 2004. 86 p (Embrapa MeioNorte. Documentos, 86).

BOTANICAL JOURNAL OF THE LINNEAN SOCIETY. An update of the Angiosperm Phylogeny Group classification for the orders and families of flowering plants: APG III b. Botanical Journal of the Linnean Society, v. 161, p. 105 - 121, 2009.

BRAND, M. A.; OLIVEIRA, L. C.; MARTINS, S. A.; LACERDA, S. R.; SOUTO JÚNIOR, L. Potencialidade de uso de biomassa de florestas nativas sob manejo sustentável para a geração de energia In: CITENEL - CONGRESSO DE INOVAÇÃO TECNOLÓGICA EM ENERGIA ELÉTRICA, 5.; 2009, Belém. Anais... Belém, 2009, p. 29.

BRAND, M. A.; STÄHELIN, T. S. F.; FERREIRA, J. C.; NEVES, M. D. Produção de biomassa para geração de energia em povoamentos de Pinus taeda L. com diferentes idades. Árvore, Viçosa, v. 38, n. 2, p. 353 - 360, 2014.

BRASIL. Lei $\mathbf{n}^{\circ}$ 11.284, de 2 de março de 2006. Dispõe sobre a gestão de florestas públicas para a produção sustentável. Disponível em: <http://www4.planalto.gov.br/legislacao/legislacao-1/leisordinarias/legislacao-1/leis-ordinarias/2006\#content>. Acesso em: 17/05/2012.

BRASIL. MINISTÉRIO DO MEIO AMBIENTE. Serviço Florestal Brasileiro. Disponível em: <http://www.florestal.gov.br/snif/recursos-florestais/os-biomas-e-suas-florestas>. Acesso em: 10/05/2012.

FRANCELINO, M. R.; FERNANDES FILHO, E. I.; RESENDE, M.; LEITE, H. G. Contribuição da caatinga na sustentabilidade de projetos de assentamentos no sertão norte-rio-grandense. Árvore, Viçosa, v. 27, n. 1, p. 79 - 86, 2003.

FUNDAÇÃO INSTITUTO BRASILEIRO DE GEOGRAFIA E ESTATÍSTICA (IBGE). Manual técnico de vegetação brasileira. Rio de Janeiro, 1992. 
GIUlietTI, A. M.; BOCAGE NETA, A. L.; CASTRO, A. A. J.; ROJAS, C. F. L. G.; SAMPAIO, E. V. S. B.; VIRGÍNIO, J.; HARLEY, R. M. Diagnóstico da vegetação nativa do bioma Caatinga. In: SILVA, J. D., TABARELLI, M., FONSECA, M. D., \& LINS, L. V. Biodiversidade da Caatinga: áreas e ações prioritárias para a conservação. Brasília: Ministério do Meio Ambiente, 2004, p. 48 - 90.

MEDEIROS, R. M. de; SANTOS, D. C. dos; SOUSA, F. de A. S. de; GOMES FILHO, M. F. Análise climatológica, classificação climática e variabilidade do balanço hídrico climatológico na bacia do rio Uruçui-Preto, PI. Revista Brasileira de Geografia Física, v. 06, n. 04, p. 652 - 664, 2013.

OLIVEIRA FILHO, A. T.; JARENKOV, J. A.; RODAL, M. J. N. Floristic relationships of seasonally dry forests of eastern South America based on tree species distribution pattern. In: PENNINGTON, R. T.; LEWIS, G. P.; RATTER, J. A. Neotropical savannas and seasonally dry forests. Boca Raton: CRC Press, 2006, p. 159 - 190.

PAREYN, F. G. C. Os recursos florestais nativos e a sua gestão no estado de Pernambuco - o papel do manejo florestal sustentável. In: GARIGLIO, M. A.; SAMPAIO, E. V. de S. B.; CESTARO, L. A.; KAGEYAMA, P. Y. (Orgs.). Uso sustentável e conservação dos recursos florestais da caatinga. Brasília: Serviço Florestal Brasileiro, 2010, p. 99 - 112.

PAUPITZ, J. Elementos da estrutura fundiária e uso da terra no semiárido brasileiro. In: GARIGLIO, M. A.; SAMPAIO, E. V. de S. B.; CESTARO, L. A.; KAGEYAMA, P. Y. (Orgs.). Uso sustentável e conservação dos recursos florestais da caatinga. Brasília: Serviço Florestal Brasileiro, 2010. p. 49 - 62.

PROJETO PNUD/FAO/IBAMA/BRA/87/007. Plano de manejo florestal para a região do Seridó do Rio Grande do Norte. Natal: Ministério do Meio Ambiente, Instituto Brasileiro do Meio Ambiente e dos Recursos Naturais Renováveis, 1992.

RAMOS, M. A.; ALBUQUERQUE, U. P. de. The domestic use of firewood in rural communities of the Caatinga: How seasonality interferes with patterns of firewood collection. Biomass and Bioenergy, v. 39, p. 147 - 158, 2012.

RAMOS, M. A.; MEDEIROS, P. M. de, AlmeIDA, A. L. S. de; FEliCiANO, A. L. P.; ALBUQUERQUE, U. P. de. Use and knowledge of fuelwood in an area of Caatinga vegetation in NE Brazil. Biomass and bioenergy, v. 32, p. 510 - 517, 2008.

SÁ, J. A. G. M. de. Avaliação do estoque lenhoso do sertão e agreste pernambucano: inventário florestal do estado de Pernambuco. Recife: PNUD/FAO/IBAMA/GOVERNO DE PERNAMBUCO, 1998. $75 \mathrm{p}$.

SAMPAIO, E. V. de S. B. Caracterização do bioma caatinga - características e potencialidades. In: GARIGLIO, M. A.; SAMPAIO, E. V. de S. B.; CESTARO, L. A.; KAGEYAMA, P. Y. (Orgs.). Uso sustentável e conservação dos recursos florestais da caatinga. Brasília: Serviço Florestal Brasileiro, 2010. p. $29-42$.

SANTOS, J. P.; ARAÚJO, E. L.; ALBUQUERQUE, U. P. Richness and distribution of useful woody plants in the semi-arid region of northeastern Brazil. Journal of Arid Environments, v. 72, p. 652 - 663 , 2008.

TONIOLO, E. R.; LEAL JÚNIOR, G.; CAMPELLO, R. C. B. Plano de Manejo Florestal Integrado Sustentável - Projeto Energia Verde. Relatório técnico. Redenção do Gurguéia, Piauí. 2005. 66 p. 
FLORESTA, Curitiba, PR, v. 45, n. 3, p. 477 - 486, jul. / set. 2015. 